\title{
In the frame: signalling structure in academic articles and blogs
}

\begin{abstract}
Metadiscourse is now established as one of the most frequently used methods for analysing academic discourse, but one feature, frame markers, seem to have gone relatively unnoticed. Frame markers represent an important way by which authors structure their discourse for particular readers, helping them to see the coherence of arguments and guiding their thinking in the direction the author wishes to go. As a result, like all metadiscourse, it varies with audience, purpose and context and in this paper we explore this variation by studying how authors use this feature when reworking their research articles as academic blogs. Based on two corpora of 50 blog posts and 50 journal articles with the same authors and topics, we found important differences in the use of frame markers and in the distribution and frequencies of its sub-categories. The results show how writers are sensitive to reader knowledge and the kinds of assistance that expert and lay audiences may need in order to follow the author's arguments. The study thus contributes to our understanding of how writers' choices help define different rhetorical contexts and the ways that recontextualisation is accomplished across academic genres.
\end{abstract}

Keywords: recontextualisation, frame markers, academic blogs, research articles, metadiscourse

\section{Introduction}

Academics build their scholarly reputations and careers on the quality and currency of their research, but this research has to be represented so that others can understand it and judge it to be original and significant. For the best chance for this to happen, writers must present their topics, structure their arguments and signal connections in ways that their readers are likely to find familiar and convincing. Awareness of an active, participating audience is crucial as writers attempt to tie texts together to make them both internally cohesive and coherent to target readers. In other words, writers shape their arguments to accommodate the probable knowledge, interests, rhetorical expectations, and processing abilities of their readers so that they will recover the writer's preferred interpretations and goals. This readerorientation in texts is often referred to as interactive metadiscourse (Hyland, 2005; Hyland \& Tse, 2004) and concerns the ways of organising discourse thus, revealing the extent to which 
the text is constructed with the reader's needs in mind.

One of the most important but least discussed features of interactive metadiscourse is frame markers, or references to rhetorical elements of text structure, such as in conclusion, there are several reasons for this, and my purpose is. Alternative conceptualisations, however, help shed some light on this device. For example, Dahl (2004) considers 'rhetorical metatext' (p. 1812) which assists the reader in processing a text by "making explicit the rhetorical acts performed by the writer in the argumentation process" (ibid. 1812). But her categorisation is limited to discourse verbs and excludes functionally related features. On the other hand, Crismore et al (1993) and Perez-Lantada (2010) split what we see as a coherent set of linguistic purposes into functionally distinct categories. Crismore et al's labelling of topicalisers, sequencers, announcements and illocution markers, for example, and PerezLlantada's separation into focusing, summarising, exemplifying, arguing, and so on, fail to recognise a rhetorical agreement: an underlying unity of purpose designed to explicitly frame the discourse to make it coherent, intelligible and persuasive to a particular audience.

In this paper, we focus on this key feature of academic texts to explore its role in shaping research for two very different audiences: disciplinary peers and non-specialist lay readers. Examining 50 academic blog posts corresponding to 50 previously published research articles written by the same authors on the same topics, we address the following questions:

(1) What role do frame markers play in organising discourse for particular target readers?

(2) What differences are there in the use of frame markers by the same authors to report the same information in journal articles and academic blogs?

\section{Frame markers in academic texts}

The notion of 'frame' emerged in metadiscourse analysis in Hyland's (2005) categorisation of interactive metadiscourse to denote indeterminate rhetorical units of texts which are explicitly marked to assist readers to follow the unfolding discourse. Frame markers refer to language devices which either signal text boundaries, mark elements of text structure, label stages, announce discourse goals, sequence material or shift arguments (Hyland, 2005, 2019). The term thus recognises that the production of coherent discourse involves consideration of readers and seeks to bring together a number of related text structuring signals in writing. It attempts to clarify several functions of textual metadiscourse proposed by Crismore et al. (1993) and to modify the notion of discourse markers in conversation (Shiffrin, 1987). Like 
these concepts, frame markers signal relations between stretches of talk and so make information easier to process and more salient, but they include more functions and forms in doing so. Unfortunately, Hyland does not elaborate the concept in his work, and it has received less attention than other features of metadiscourse in the literature.

Essentially, frame markers indicate text boundaries or functional structures. They therefore exclude items such as however, although and nevertheless which are referred to as conjunctives by Halliday \& Hasan (1976) and logical connectives by Martin \& Rose (2003). These sentence connectors are called transitions in the metadiscourse model (Hyland, 2005, 2019). Their function is to express the relationship between clauses or sentences and they typically signal additive, contrastive, consequential and concessive connections (Hyland, 2005).

Similarly, the items included as 'code glosses' (e.g. that is to say, such as) in the metadiscourse model (Hyland, 2005, 2019) are restricted to offering more information about a word or phrase, by signalling an example, a repetition or a rephrasing. Frame markers, on the other hand, help organise larger segments of texts to explicitly spell out to readers where the argument is going and what the writer intends to do next. They therefore have two main roles a) to signal directions and changes in the ongoing text and b) to signal an interactive relationship with readers, indicating that their text processing needs are being taken into account. In this way they contribute to both cohesion and coherence, meaningfully connecting and ordering chunks of texts to accommodate readers' understanding of the discourse.

Like other features of metadiscourse, frame markers are internal to the text. They identify or order arguments in the text rather than events in the real world, that is, the ideas in the text. They are used to sequence material, label text stages, announce discourse goals and indicate topic shifts (Hyland \& Tse, 2004; Hyland, 2005). They are thus concerned with making the textual world accessible and meaningful to readers by configuring discourse units of various size for them. They achieve the pragmatic functions of organizing a text both locally and globally and reducing readers' processing effort (Aguilar, 2008).

Specifically, according to Hyland (2005), frame markers are further subdivided thus:

- Sequencers: used to sequence parts of the text or to internally order an argument (e.g. 
there are several reasons why, first, then, 1, 2, a, b, at the same time, next).

- Labellers explicitly label the function of the following stage or upcoming text. Often these indicate the speech act that will be performed, either encapsulating aspects of the prior text (to summarize, in sum, thus far) or signal what the following text is intended to do (by way of introduction, to repeat)

- Goal announcers state the author's purpose in the text (I argue here, my purpose is, the paper proposes, I hope to persuade). The marker may refer to the overall purpose of the paper or to local, more immediate goals in a specific part of the text.

- $\quad$ Topic shifters indicate a shift in the direction of the text (right, OK, now, let us return to, with regard to).

Frame markers, therefore orchestrate the overall organisation of the discourse to guide readers in recovering the writer's message. By communicating a clear purpose and direction, signposting lines of argument and holding the components of a text together, the writer makes the rhetorical acts performed in the argument explicit (Dahl, 2004) and attempts to carry the reader along with it. The sensitivity of frame markers to their rhetorical context means that studies have shown variations in their use, so that they tend to be more frequent, for example, in quantitative than qualitative research articles in the social sciences (Cao \& $\mathrm{Hu}, 2014)$.

Studies have also found different frequencies and uses of frame markers across genres, languages, disciplines and time. El-Dakhs (2018), for instance, found that the space constraints placed on research article abstracts in applied linguistics meant that writers used far more listing sequencers compared with writers of $\mathrm{PhD}$ theses abstracts. In another crossgenre study, Hempel and Degand (2008) found that academic writing makes far greater use of sequencing frame markers compared with broadsheet journalism and fiction. In terms of discipline, Khedri et al. (2013) showed that abstracts in applied linguists contained significantly more frame markers to mark text boundaries, show discourse organization and indicate the shape of the unfolding discourse than those in economics.

Cross-linguistically, studies have shown differences in the use of frame markers in research articles written in English and in other languages such as Chinese, Spanish and French (Mu et al., 2015; Mur-Dueñas, 2011; Kim \& Lim,2013). Dahl (2004), for instance, investigated 
interactive metadiscourse in research articles across three languages (English, Norwegian and French) and disciplines (economics, linguistics and medicine). While placing linguistic constraints on this functional category, she found English and Norwegian economics and linguistics articles displayed a similar number of frame markers, whereas the French texts made much less use of this device. Frequencies were almost identical across three languages within medicine. From a diachronic perspective, Hyland and Jiang (2018) analysed the use of frame markers in high impact factor journals across contrasting disciplines over the past 50 years, showing an overall increase of $15 \%$ per 10,000 words. There has been, however, a decline in the soft disciplines and a rise in the hard sciences, with electrical engineers being the heaviest users.

In sum, frame markers are a pervasive feature of writing and are used to help readers make their way through an unfolding discourse. It is clear that, like all metadiscourse resources, they are influenced by their social and rhetorical context, but it is less clear how writers modify their use when rewriting content for another purpose and audience. We address this gap by examining the choices writers make when transforming their published research into academic blog posts.

\section{Academic blogging and recontextualisation}

One of the most significant changes in scholarly communication in recent years has been the growth of academic blogging, which is now an established communication channel in both the physical and social sciences (e.g. Kurteeva, 2016). On the one hand, this development has been encouraged by internet affordances such as information archiving, hyperlinking to sources, wide distribution and opportunities for immediate commentary. On the other hand, blogs have become important as universities increasingly admonish academics to take their research to wider audiences. Thus, as a means of increasing the visibility of both research and the researcher, the academic blog offers a new outlet for scholars to share and discuss scientific issues and disseminate their own research to a broader readership. They are intended to be read not by specialists but by multiple publics, with shared interests, including other academics.

The literature suggests that blog posts are not intended to be read only by specialists in a discipline, but multiple publics with shared interests to create a sense of community that transcends institutional and disciplinary boundaries (Blanchard, 2011). The LSE Impact site, 
from which our blog corpus was drawn, states that it is

a hub for researchers, administrative staff, librarians, students, think tanks, government, and anyone else interested in maximising the impact of academic work in the social sciences. (LSE Impact Blog)

Blogging has also been recognised as a powerful tool for reflection and has been used for researcher development by doctoral students (Ward \& West, 2008), established academics (Steel, Cohen, Hurley, \& Joy, 2012) and researchers (Gruzd et al., 2012), or like-minded individuals with a decided interest in academic information. They act as 'virtual water coolers' (Kouper, 2010) around which the lay public can participate in debates and perhaps help create a sense of community that transcends institutional and disciplinary boundaries (Blanchard, 2011).

Creating blogs from material previously published by the author in a research article obviously involves considerable recontextualization (Linell, 1998) or intralinguistic translation (Gotti, 2014). Information has to be redrafted and remodelled to suit a new target readership. (Zou \& Hyland, 2019). By breaking down boundaries between public and private discursive practices, blogs give shape to a more informal style which makes fewer demands on readers' subject knowledge and specialized interests. Because they are more accessible, both rhetorically and financially, than research papers, blogs are also less top-down and oneway, providing a perpetual feedback loop of online communications (Andrews, 2003). This means that writers orchestrate a variety of strategies to so that a new readership can comprehend the discourse and integrate information into their existing knowledge (Luzón, 2013; Zou \& Hyland, 2019).

Recontextualisation, involving fitting some aspect of a text into another, has long interested linguists to explain how information can be appropriated and manipulated for different contexts (Bauman \& Briggs, 1990; Bernstein, 1990; Linell, 1998). It is a defining feature of digitally mediated discourse, and so it is unsurprising we find it in academic blogs (e.g. Kuteeva \& Mauranen, 2018). In most cases, the contents of academic blog posts are closely related to the research articles in which they might originate, but with specialised scientific information re-modelled for a new readership and the demands of different communicative purposes. Recontextualisation therefore involves, among other changes, writers making 
decisions regarding how best to restructure lines of argument, set out discourse purposes, signal text directions and manage rhetorical connections (Hyland \& Jiang, 2018).

Writing for a potentially heterogeneous audience of academics and lay people means that bloggers must avoid the lengthy, sustained argumentation of the journal article and offer a more succinct and reader-friendly presentation. Some of the changes required to create more appropriate interpersonal connections with readers in blogs have been discussed by Zou and Hyland (2019), who explored stance and engagement choices, and Luzón (2013), who analysed rhetorical strategies such as self-disclosure and reference to readers to engage the diverse audience. We are, however, aware of no studies which have examined discourse organising changes.

Rather than comparing the rhetorical decisions of individual authors at specific points in their texts, we take a wider view to explore structural differences in two parallel corpora. We are then, less concerned with the on-line cognitive processing of writing and more with the different purposes for which language is being used. That is to say, we focus on recontextualisation and the text level changes which are the result of authors' understandings of the two genres and the needs of different audiences. Without access to the internal workings of writers' minds, this is the most concrete and visible realisation of writers' rhetorical decision-making. It overcomes individual judgments and stylistic quirks, allowing us to see the typical characteristics of the genres rather than of the authors. In other words, corpora offer us an aggregate of these decisions, indicating how individuals, acting as members of disciplinary communities, chose to most effectively present their research in different contexts for different audiences. These comparisons will, we hope, contribute to how we understand academic blogs, the role of frame markers, and how context, communicative purposes and different readerships, shape writers' rhetorical choices.

\section{Corpora and analytical approach}

To trace how writers rhetorically recontextualise the lines of argument from their journal articles to academic blogs, we compiled two corpora. A corpus of blogs comprising 50 posts corresponding to a corpus of 50 previously published research articles written by the same authors on the same topics. We matched texts in this way to avoid the influence of different writing styles on writing choices, minimising individual writers' personal preferences and idiosyncrasies while collecting sufficient samples for us to see the typical characteristics of 
the genres themselves. We selected the posts from the popular LSE Impact Blog website, which is hosted by the London School of Economics and Political Science. ${ }^{1}$ As one the earliest and most established international sites in the social sciences, it hosts thousands of academic posts and seeks to promote discussions of the latest research trends, to exchange and disseminate research findings and to encourage debate among the wider public. It is widely recognised as a major forum for scholars featuring research in subjects like policy, society and education, and for bringing diverse voices and stakeholders together into academic discussions.

All the submitted posts undergo a review process by the editors to ensure the novelty, interest and readability. Then, they are published on the site within two weeks after revisions. The word limit for each post is 1,000 words. The audiences, according to the website, primarily comprise researchers, higher education professionals, policymakers, research funders, students and those who have interested in the issues raised. The website encourages sharing best practice among diversified readers and claims more than 70,000 readers each week.

Our criteria for selecting blogs from the LSE website were:

1) Posts and papers published between 2012 to 2019 to ensure currency;

2) Posts related to a recently published journal article by the same author on the same topic;

3) Journal articles published in peer-reviewed journals in the social sciences.

Following these guidelines, we collected 50 blog posts comprising 50 texts of 52,743 words and 50 corresponding journal articles of 291,899 words. Details of the corpora are presented in Table 1. We note the word length differences across the two corpora and how this is likely to influence authors use of frame markers, but all comparisons are normed to a base of 1000 words to ensure comparability.

Table 1 Corpus size and composition

\begin{tabular}{lcc}
\hline & Number of texts & Total number of words \\
\cline { 2 - 3 } Academic blog posts & 50 & 52,743 \\
Journal articles & 50 & 291,899 \\
Total & $\mathbf{1 0 0}$ & $\mathbf{3 4 4 , 6 4 2}$ \\
\hline
\end{tabular}

${ }^{1}$ LSE website address: http://blogs.lse.ac.uk/impactofsocialsciences/ 
The corpora were searched for potential frame markers, using AntConc (Anthony, 2018). The search inventory comprised a general list of features (see Appendix) including its subcategories of sequencers, labellers, goal announcements and topic shifters in Hyland's model (2019). Additional items were also added after a thorough reading of all the texts. All retrieved items were manually checked to ensure that each performed the function to which it was assigned, and an inter-rater agreement of $96 \%$ was reached after each author independently coded a $30 \%$ sample of each corpus. Intra-reliability tests were also conducted by the first author re-categorizing $20 \%$ of the cases two weeks after the initial coding with full agreement between the first and second categorizations achieved. Finally, the frequencies of features in each category were calculated after normalising the results to 1,000 words and then analysed using the Statistical Package for the Social Sciences (SPSS) to determine statistical significances. The results will be discussed in the following sections.

\section{An overview of frame markers in the two genres}

Overall, we found 319 frame markers in the blogs and 1,278 in the journal articles. When normed for text length, this amount to 6.04 per 1,000 words in the blogs compared with 4.38 in the articles. The details are presented in Table 2.

Table 2 Frame markers in the two genres (per 1,000 words \& \%)

\begin{tabular}{lcccccc}
\hline & \multicolumn{3}{c}{ Academic blog posts } & \multicolumn{3}{c}{ Journal articles } \\
& $\begin{array}{l}\text { total } \\
\text { cases }\end{array}$ & $\begin{array}{c}\text { per } 1,000 \\
\text { words }\end{array}$ & $\%$ & total cases & $\begin{array}{c}\text { per } 1,000 \\
\text { words }\end{array}$ & $\%$ \\
Sequencers & 218 & 4.13 & 68.34 & 467 & 1.60 & 36.54 \\
Labelers & 84 & 1.59 & 26.33 & 705 & 2.42 & 55.16 \\
Goal announcers & 15 & 0.28 & 4.70 & 77 & 0.26 & 6.03 \\
Topic shifters & 2 & 0.04 & 0.63 & 29 & 0.10 & 2.27 \\
Total & $\mathbf{3 1 9}$ & $\mathbf{6 . 0 4}$ & $\mathbf{1 0 0 . 0 0}$ & $\mathbf{1 2 7 8}$ & $\mathbf{4 . 3 8}$ & $\mathbf{1 0 0 . 0 0}$ \\
\hline
\end{tabular}

The results clearly indicate that academics are conscious of the need to appropriately structure lines of arguments in both genres. However, perhaps surprisingly, there were significantly more frame markers in the blog posts than research articles per 1000 words (log Likelihood $=10.997, \mathrm{p}<0.01$ ). The very different rhetorical purposes and target readerships of each genre help account for this. In both genres, frame markers function to aid comprehension of the ongoing text, but many of the connections between ideas in research 
articles are extratextual: they are not spelled out in the discourse but supplied by the context and by the assumed inferences the expert audience is presumed to be in a position to make (Fahnestock, 1986). In blogs, on the other hand, a readership with potentially less subject knowledge is likely to require more assistance in seeing connections and working their way through a text. As a result, explicit acts labelling aspects of the argument or content have to be supplied, rather than presupposed, to assist text processing. The greater number of frame markers in this genre therefor compensates for a relative lack of content knowledge and reduces the processing effort required to work through it.

Looking at the sub-categories, we see that sequencers were significantly more frequent in the blogs $(\log$ Likelihood $=31.944, \mathrm{p}<0.0001)$, with nearly 2.6 times as many cases as in the research articles. Goal announcers showed slightly more use in blogs, but the difference was not significant $(\log$ Likelihood $=-2.695, \mathrm{p}<0.794)$. Labellers and topic shifters, in contrast, were significantly more common in journal articles ( $\log$ Likelihood $=11.887, \mathrm{p}<0.01$ for labellers, $\log$ Likelihood $=5.151, \mathrm{p}<0.07$ for topic shifters). In transforming specialized knowledge for lay readers in the process of reformulating the content of their articles to blog posts, we find writers taking far more trouble to clearly spell out the progression of material at the expense of naming items and explicitly changing the direction of the argument. In the following sections, we look at each sub-category of frame markers in turn.

\section{Sequencers: marking structure}

Sequencing devices function to facilitate the reader's understanding of the message by making explicit the structure of the propositional content or some element of it (Hyland, 1998). A sequencing device usually consists of two parts: first, often (but not always) a sequence introducer (such as so, thus, there are 3 reasons for this, this gives us 2 possible answers), and second, one of the following types of sequence indicator:

- listing sequencers, such as numbers $(1,2,3)$, bullet points, roman numerals (i, ii, iii) or letters $(\mathrm{a}, \mathrm{b}, \mathrm{c})$;

- $\quad$ numerical sequencers (adjective/adverbial phrases such as first, secondly, first of all);

- temporal sequencers (adjective/adverbial phrases such as next, finally, to begin with).

It is worth noting that the classification is strictly formal, so that listing sequencers perform the same role as numerical and temporal types but do so non-linguistically. They are, 
however, almost always prefaced by sequence introducers signalling a series such as thus, so, there are three reasons for this (which make up $80 \%$ of introducers in our corpora). Together, these offer the most explicit way of labelling stages or ordering an argument. We should note that a) we counted introducers and indicators separately for our analysis as they do not always occur as pairs and b) that we counted indicators as groups not individual items, so that 3 dot points, for example, were recorded as one unit of indicators. In our corpora, sequencers comprise the largest proportion of frame markers in the blogs, accounting for over two thirds of all cases, and over a third in the articles.

Clearly, with the need to organise material for an audience possessing an indeterminate knowledge base and uncertain experience of following academic arguments, writers take more trouble to spell out their points. Deploying sequencers can simplify long sentences, thus increasing readability. So clearly, the shorter length of academic blogs make these sequencers especially attractive to writers, as has been found when comparing sequencers in fictional versus academic texts (Hempel and Degand, 2008) and article vs PhD abstracts (El-Dakhs, 2018). Text length, however, is just one factor. Blogs are not summaries or abstracts of articles but are a different genre altogether, with different patterns of argument and reader engagement patterns. Sequencers do not simply save space, more importantly they attempt to make the presentation clearer and demonstrate a consideration for readers. They also add an aesthetic element to the presentation to make the process more enjoyable and so further engage readers and encourage them to stick with the task.

Most importantly, however, sequencers offer a resource for clarifying the presentation and guiding readers by overt marking of steps in a process, stages of an argument, or aspects of an idea. Sequencers are, moreover, the most versatile category of frame markers in terms of their scope as they can be used to organise the entire text (1) or a limited part of it, such as reviewing conclusions (2) or setting out ideas (3):

(1) In this article, we (1) compare societal impact practices in the social sciences and humanities in high-performing countries (HPCs) and low-performing countries (LPCs) ... and (2) reflect upon consequences for the competition for research funding in the European funding arena. (RA 41) ${ }^{2}$

\footnotetext{
${ }^{2} \mathrm{BP}$ refers to the blog post corpus and RA the research article corpus and the number identifies the text.
} 
(2) We concluded that there were three take away messages from these literature reviews:

i) Knowledge mobilisation is a social process

ii) Efforts to enhance Knowledge mobilisation need to be interactive ...

iii) Knowledge mobilisation happens at the level of the individual .... (BP19)

(3) I outline three explanations below, all of which probably have some merit:

- Women's research is not sufficiently recognised or valued by our universities or the academy....

- Female academics may take on a greater proportion of the teaching and administrative roles within the academy....

- Women are actively seeking new opportunities to undertake research and dissemination activities that do not involve publishing. ... (BP 20)

Clearly, the more elaborate and discursive nature of the articles requires more text structuring sequencers such as numbers (Example1) to indicate research processes. Blogs, at only 1000 words, present their arguments more succinctly and so do not require explicit marking of text stages and the argument simply proceeds stepwise without any organising metadiscourse.

Instead, sequencing in blogs is generally more local, often acting to signal additive relations, whereby items are shown as augmenting or aggregating each other as in (2) and (3) (Hyland, 2019). Table 3 shows the distribution of the different categorisation of sequencers in the two genres.

Table 3. Sub-categories of sequencers in the two genres (per 1,000 words $\& \%$ )

\begin{tabular}{lcccc}
\hline & \multicolumn{2}{c}{ Academic blog posts } & \multicolumn{2}{c}{ Journal articles } \\
& per 1,000 words & $\%$ & per 1,000 words & $\%$ \\
\cline { 2 - 5 } Listing sequencers & 2.41 & 58.25 & 0.30 & 19.05 \\
Numerical sequencer & 0.51 & 12.39 & 0.96 & 59.96 \\
Temporal sequencer & 1.21 & 29.36 & 0.34 & 20.99 \\
Total & $\mathbf{4 . 1 3}$ & $\mathbf{1 0 0 . 0 0}$ & $\mathbf{1 . 6 0}$ & $\mathbf{1 0 0 . 0 0}$
\end{tabular}

As we can see, listing and temporal sequencers were more frequent in blogs, with the differences statistically significant $(\log$ Likelihood $=33.937, \mathrm{p}<0.0001$ for listing sequencers; $\log$ Likelihood $=24.740, \mathrm{p}<0.0001$ for temporal). On the other hand, numerical sequencers were significantly more frequent in research articles $(\log$ Likelihood $=13.125, \mathrm{p}<0.005)$, 
accounting for more than half of all sequencers in the journal article corpus.

\section{i) Listing sequencers}

Listing sequencers seem to fit the hybridity of academic blogs rather better than temporal or numerical marking, drawing not only on scholarly written genres but also spoken ones such as conference talks and social media discourses (Grafton, 2009; Mauranen, 2013). These tend to give more attention to the visual impact of the text, bringing greater clarity to the presentation of scientific information and contrasting with the dense, technical prose of academic articles (Ledin \& Machin, 2015). Spatially distinguishing items in this way not only gives greater prominence to items but also simplifies the presentation of relationships and connections, facilitating efficient scanning and processing of the material. Listing sequencers can therefore, help present the topic to general readers and encourage them to engage with the topic. This objective seems to be most effectively achieved through the use of bullet points, which are favoured by authors when moving their research into blogs (See Table 4).

Table 4. Sub-categories of listing sequencers in the two genres (per 1,000 words \& \%)

\begin{tabular}{lcccc}
\hline & \multicolumn{2}{c}{ Academic blog posts } & \multicolumn{2}{c}{ Journal articles } \\
& per 1,000 words & $\%$ & per 1,000 words & $\%$ \\
\cline { 2 - 5 } Number (1,2,3) & 0.97 & 40.16 & 0.19 & 62.92 \\
Bullet point (•) & 1.40 & 58.27 & 0.06 & 20.22 \\
Roman numeral (i, ii, iii) & 0.04 & 1.57 & 0.03 & 8.99 \\
Letters (a,b,c/A,B,C) & 0.00 & 0.00 & 0.02 & 7.87 \\
Total & $\mathbf{2 . 4 1}$ & $\mathbf{1 0 0 . 0 0}$ & $\mathbf{0 . 3 0}$ & $\mathbf{1 0 0 . 0 0}$ \\
\hline
\end{tabular}

Bullet points display the greatest genre variation with statistically far more cases in blogs (log Likelihood $=29.312, \mathrm{p}<0.0001$ ). The fact that they present ideas in an aesthetic and visually attractive way, permit text brevity, make texts accessible and quicker to scan means they are perfectly suited to blogs. They therefore represent a conscious choice by writers to set things out in a way most likely to be understood by lay readers. An idea of the processing ease achieved by use of bullet points can be seen in the example below of the same material in a blog (4) and article (5):

(4) Overall, our review identifies several approaches that show some promise for improving the use of research in population health policy: 
- A system for commissioning rapid reviews

- Tailored approaches to presenting research findings to policymakers

- The involvement of policymakers in research teams and networks

- Interactive seminars and conferencing technology for communicating evidence

- Initiatives to build capability in people and across organisations

- Funded institutional-level collaborations. (BP1)

(5) This review provides additional preliminary support for the potential value of research in population health policy: a system for commissioning rapid reviews; tailored approaches to presenting written research findings to policy audiences; the involvement of policy makers in research teams and networks; interactive seminars and conferencing technology for communicating about evidence; organisation-wide capability development initiatives; and funded institutionallevel collaborations. (RA1)

Bullet points are considered to epitomise new writing practices and the marketization of public discourse (Djonov \& Leeuwen, 2014). They are principally popular, however, as they enable long and complex information to be put across quickly (Hansen, 2016), conveying material in an easy manner which avoids bogging audiences down with long and wordy passages. In one extract from our corpus, for example, a numerically sequenced paragraph of 284 words in an article was reworked as a 3 point bulleted list of 168 words in a blog. Overall, there seems to be some uncertainty about the acceptability of bullet points in research articles and writers overwhelmingly favour numerical marking, even where there is no obvious reason why items should be sequenced.

\section{ii) Numerical sequencers}

Writers in research articles employ a more established set of rhetorical conventions to facilitate the creation of shared community knowledge. Argument patterns are generally more familiar to the disciplinary cognoscenti who can process the unfolding texts and track connections with greater ease without the need for spatially augmented sequencers. In this genre writers favour the use of numerical sequencers. These contribute to the clearness and legibility of the text (Hempel \& Degand, 2008), indicting what the writer is going to do and laying out the structure, without the readability aid of white space. 
In our journal article corpus, numerical sequencers have an inter-sentential scope, normally preceded by an introductory phrase, containing a classifier (limitations/points) and a specified quantifier (two) (examples 6 and 7). This structural signposting is the most common textual device used in articles to present, in an explicit way, research-based arguments, reasons, evidence, procedures or findings:

(6) Because of budgetary restrictions, our information on productivity suffers from two limitations. Firstly, the article count in our dataset made no distinction between single and multiple-authorship... Secondly, although we know the journal where each article is published, it was impossible to search for the citation impact achieved by every article. (RA17)

(7) We emphasize the following two points. First, in both samples, the data show a clear funnelling effect towards the US. ... Second, besides the US, the economists in the total sample belong to 61 different countries.... (RA18)

\section{iii) Temporal sequencers}

Temporal sequencers, are also considerably more predominant in blogs, although with half the frequency of listing devices. Indicating chronology and importance, the temporal sequencer is a rhetorical strategy which exploits the association blogs have with conversational sharing, presenting information and ideas through personal experience and narration rather than reliance on established measures of objective proof (Zou \& Hyland, 2019). This suits the storytelling nature of blogs, setting out chronological progression. In addition, temporal sequencers also cater to the descriptive information needs of the heterogenous audiences of blogs, assisting readers to recover activities and processes easily:

(8) Looking specifically at graduate education, we split our total sample into three groups: ... We then looked at where our economists obtained their PhDs (BP18)

(9) I then decided that I needed a way of preserving, curating and sharing all the interesting blog posts and news articles that I had discovered via Twitter.... I then discovered Pinterest, a curating platform for images, and found that it provided a fascinating way to collect images relevant to my research. (BP 42)

\section{Labellers: naming discourse acts}

Labellers are frame markers which signal the current discourse activity and offer an explicit 
means for writers to mark upcoming text stages or rhetorical functions. They are a type of what Fraser (1988) calls 'discourse activity markers' which refer to types of discourse work such as explaining or summarising, and not to the type of message the speaker conveys through the utterance. Their use is motivated by the writer's concern to both underscore the rhetorical function of the immediate text and to indicate progression of the discourse (Rahman, 2004). Labellers can serve the purpose of keeping the reader abreast of the developing argument, but they do so by naming the illocutionary purpose of the immediate text, what the writer intendeds it to do. We might, then, expect labellers to be more common in the blogs than the articles, after all, an audience less conversant with the subject matter of the text might need a little more help in following it. However, we surmise that writers might feel something less structurally formal, such a bullet point sequencer, might be better suited to an audience with potentially less experience of, and perhaps respect for, the traditional layout and section naming of research prose. Because of this they comprise over half of all frame markers in the articles, significantly more than in blogs (log Likelihood=11.887, $\mathrm{p}<0.01)$. They also make up a quarter of all markers in the blogs, indicating their importance to writers in both genres.

Labellers explicitly name acts which require the readers to take particular notice and so seek to grab their attention at points in the discourse. In the articles these acts most commonly summarise or draw conclusions from an argument, as here:

(10) In sum, we therefore suggest that researchers with a positive perception about institutional support for engaging with non-academic agents are more open. (RA 48)

(11) In summary, analysis across the disciplines shows that women published fewer articles than their male colleagues in three out of the four disciplines. (RA20)

Explicitly pointing out how readers should interpret the preceding discourse is obviously a useful strategy to guarantee that they will get the writer's take-home message. A similar desire to highlight aspects of the argument can be seen in labellers which do not point backwards to what has been, but which pause the discourse to explicitly refer to the stage it has reached and signal what will come next:

(12) We will consider Section 2 of the act later in this paper but at this point it is appropriate to briefly address Section 3 of the Act which.... (RA17) 
(13) Here I contrast that with the learning networks which I inhabit, and in which every single day I share my learning. (RA 15)

However, while the use of labelling to review key points in the text, or emphasize those which are about to enter it, seem to be conventional rhetorical strategies in the articles, writers are reluctant to use them in the blog posts. There are a number of reasons for this. First, blogs are much shorter than articles, often 1000 words rather than $8,000-10,000$, and so contain fewer complex arguments and make fewer points. This brevity means that there is less need for regular summaries and highlighting of the main points. Therefore, although they are not specialists, educated readers might reasonably expected to hold the ideas in their head for 6 or 8 paragraphs.

Second, in such short texts, any effort to constantly summarise and draw readers attention to points perhaps carries a degree of condescension, banging readers over the head with what has only just been mentioned. The cognitive load imposed by such short texts means that readers don't need to be reminded so frequently of what they are reading and to do so might seem patronizing to the lay audience. Third, and most significantly, blogs are constructed in a less linearly argumentative style than articles. They are more narrative, often avoiding the detailed analyses, literature critique and citations which typically support research claims in papers. Instead, they tend to be more concrete and often describe a piece of research as a story with greater use of metaphor and multiperspectivity. So, if the discussion is clear and pitched at an appropriate level for the audience, then writers may see less need to label parts of the text so frequently.

Thus, in blogs, the focus is centred more on attempting to create a dialogue with readers, seeking to engage them in the topic in a more involved way without too many trappings of formal academic writing. Moreover, as Stiles (1981) observes, summaries are reflections and this may require considerable cognitive effort to digest. While forms such as in conclusion are not unknown, writers tend to draw on less formal forms of labelling, highlighting main points by more conversational types of marker to help readers get the take-home message of the argument and make connections between research and real-life, as here:

(14) So what does this tell us about blogging and student engagement? (BP 6) 
Variations can not only be seen in the choice of labelling items but also in the form they take. Labelling resources can be sub-categorised into those presented as subheadings (e.g. Four types of definitions, What did we measure in this study?) and those that are not, with the former being more frequent in blog posts, and the latter significantly more common in the research articles $(\log$ Likelihood $=-2.050, \mathrm{p}<0.74$ for subheading labellers and log Likelihood $=38.196, \mathrm{p}<0.0001$ for non-subhead labellers). Table 5 shows these differences.

Table 5 Sub-categories of labelling in the two genres (per 1, 000 words \& \%)

\begin{tabular}{lcccc}
\hline & \multicolumn{2}{c}{ Academic blog posts } & \multicolumn{2}{c}{ Research articles } \\
& per 1,000 words & $\%$ & per 1,000 words & $\%$ \\
\cline { 2 - 5 } Subheading labelers & 1.21 & 76.19 & 1.03 & 42.84 \\
Non-subhead labelers & 0.38 & 23.81 & 1.38 & 57.16 \\
Total & $\mathbf{1 . 5 9}$ & $\mathbf{1 0 0 . 0 0}$ & $\mathbf{2 . 4 2}$ & $\mathbf{1 0 0 . 0 0}$ \\
\hline
\end{tabular}

The considerable genre differences here suggest that subheading labellers play an important role in recontextualising disciplinary knowledge for lay readers. These are signpost which orient and direct readers, informing them of where they are in the text and where they can find argument and support for each result (Stoller \& Robinson, 2013). Punctuating a text with such subheads is a recognized readability strategy, offering a succinct means of framing text segments, identifying what is to follow, allowing readers to locate information in which they are interested, and capturing the points of the text which follows. In other words, they facilitate the reading process for those with limited subject-knowledge expertise:

(15) Charting the impact of Blue Ocean Strategy

(BP40)

\section{(16) What we found (BP39)}

Here, subheading labellers summarise the arguments by breaking them up into clearer and more readable sections, allowing audiences to see spatially what will be discussed.

In addition, subheadings also play a crucial role in grabbing and holding the reader's attention, attracting them as they move down the text. Common web scanning practices mean that readers often do not read an entire text and need a reason to do so. By breaking up the text into chunks these subheading labellers provide that reason. This is a particularly effective strategy when, as we found in our blog corpus, they are often expressed as questions, as here. 
(17) What did we measure in this study? (BP10)

(18) Guide to inclusive conferences: why and how? (BP43)

(19) Does Green OA affect gendered citation effects? (BP8)

(20) What do we need to do differently? (BP34)

Questions are the main strategy of dialogic engagement, inviting the involvement of readers and bringing them into the discussion as participants (Hyland, 2002). By expressing the subheading as a question writers not only label what the following text is about, but also seek to create a dialogue with multiple audiences (Luzón, 2013). They therefore invite and motivate the audience to read further and find answers.

\section{Goal announcers: proclaiming goals and purposes}

Goal announcements indicate either the overall discursive purposes of the writer or the intended goals for a specific part of the text. Explicitly stating one's purposes is a powerful rhetorical tool (Hyland \& Jiang 2018) and writers are well aware of its value in signalling the direction of their argument and ensuring that readers understand where the text will take them. These signposts are also useful for establishing the core around which the argument can build on and help sharpen the writer's thinking about what it is that they are doing (Lim et al., 2015). These text initial examples are typical:

(21) The goal of this session was to devise a set of clear principles which describe what we mean by open data in the humanities (BP26)

(22) This paper aims to identify the key ethical challenges and current safeguards in using mobile digital recordings as research data, through a review of the existing literature in four key fields... (RA23)

As a result, writers used goal announcements with similar frequency in the two genres (Table 2).

There is a very clear stance positioning in announcing goals or purposes and Molino (2010, p. 92) considers this function as "the most frequent use of personal authorial references". This stance-making function is particularly explicit in blogs, which rely to a greater extent on practices of conversational sharing, so writers often present information through personal reliability rather than the authority of research findings or a disciplinary literature. By combining self-mention with goal announcements, writers emphasise their subjectivity when 
stating their research objectives and previewing their text (23). While in research articles, writers tend to downplay their personal visibility when using goal announcers, instead resorting to references or established measures of objective proof (24).

(23) We would like to find out how researchers evaluate impact (if at all), what the benefits of using social and other digital media for public engagement has been... (BP32)

(24) The objective of this study was to compare the publication patterns of students in traditional versus TD doctoral training programs. (RA 10)

In addition, goal announcers also provide motivation for readers interested in the topic and a helpful aid to those who may be less familiar with the ideas (Hyland \& Jiang, 2018). This helps account for their popularity in the blogs, as while they are shorter and perhaps require less explicit declarations of intent, the fact they are geared for multiple and diverse audiences means that explicit assistance in recovering what the writer is trying to do at various points is a helpful resource.

(25) To illustrate this point, I would like to report a session on open data in the humanities at the Open Knowledge Festival this summer. (BP26)

(26) Causality in social science is hard to establish even through the finest comparative research. To elaborate on that, we propose to focus on the distinguishing features of an examined example. (BP 45)

(27) With this caveat in mind, we can still outline the types of questions that may improve our knowledge, informed by existing research on expertise. For example, it is useful to identify the attributes that an expert is expected to possess, and what experts are expected to do. What are the roles of professional qualifications and personal experience in establishing expertise? ... (BP 33)

As a consequence, the two genres differ considerably in the scope of the announcements, with Table 6 showing that those focusing on local purposes are overwhelmingly preferred by academics when reformulating their paper in blogs. 
Table 6. Sub-categories of goal announcements in the two genres (per 1, 000 words \& \%)

\begin{tabular}{lcccc}
\hline & \multicolumn{2}{c}{ Academic blog posts } & \multicolumn{2}{c}{ Research articles } \\
& per 1,000 words & $\%$ & per 1,000 words & $\%$ \\
\cline { 2 - 5 } Overall purpose & 0.06 & 20.00 & 0.19 & 72.73 \\
Local goals & 0.23 & 80.00 & 0.07 & 27.27 \\
Total & $\mathbf{0 . 2 8}$ & $\mathbf{1 0 0 . 0 0}$ & $\mathbf{0 . 2 6}$ & $\mathbf{1 0 0 . 0 0}$ \\
\hline
\end{tabular}

Thus the clear expression of local intentions may be useful to readers with less familiarity with the disciplinary knowledge which might be needed to unpack arguments in blogs. But in research articles, writers were significantly more likely to refer to overall purposes (log Likelihood $=12.410, \mathrm{p}<0.005)$. Here, writers like to set out their stall at the outset, informing readers where they are going and hoping that readers will arrive at the same destination:

(28) This paper aims to identify the key ethical challenges and current safeguards in using mobile digital recordings as research data, through a review of the existing literature in four key fields. (RA 23)

Finally, we should point out that goal announcers do more than declare the direction of the text or proclaim local purposes. In performing these functions, they often simultaneously provide the reader with detailed explanations and clarifications. In the blogs particularly, the need for succinct presentation means that goal anouncements are accompanied by possible solutions to the issues raised, thus involving readers collaboratively in the development of the text. As the examples below show, announcers can prepare readers for what is to come while also suggesting reasons for following the expressed purpose (29) or rejecting plausibly alternative ways of proceeding (30):

(29) For this reason, we seek to understand the process underpinning the creation of usable knowledge which we define as creating knowledge most cognate with users, thereby maximising its usability and the societal returns to the research investment. We propose a way of conducting research that leads to the production of knowledge cognate with users, contributing to a knowledge base related to user's needs. (BP47)

(30) At this point a more radical person might mention the Cost of Knowledge statement started by Timothy Gowers as an example of authors involving themselves in the re-education of scholarly communication. ... I think 
those are valid talking points, but I would like to start more simply. (BP49)

\section{Topic shifters: changing text direction}

Topic shifters indicate a change in the focus of attention, moving from one point the writer wishes to raise to another. Next, now and we turn to are common signals typically embedded in an accompanying statement of intention. They are used to organise the discourse with the specific aims of either introducing a related topic (31), of changing the current topic (32), or of returning to a topic introduced earlier (33) (Mur-Dueñas, 2011).

(31) The hypotheses are tested using a database of researchers working at the CSIC. In order to better frame the testing process, we now provide an explanation of the dataset, the construction of the variables and the analytical plan. (RA 48)

(32) Next, we turn to the low-salience punctuations that receive attention through a single minor topic code but that receive limited or no media attention. (RA 35)

(33) Here we now consider the specific questions addressed in Table 1 to determine whether or not false representations that were dishonest were being made with the intention of making a gain. (RA 17)

Topic shifters were significantly more frequent in our research article corpus than in the blogs $(\log$ Likelihood $=5.151, \mathrm{p}<0.07)$. It is also true, however, that topic shifters account for the lowest proportion of frame markers in both genres. This may be because their use disrupts the flow of the discourse, causing a digression which may be hard to follow (Ionescu, 2019).

Clearly, the length of blogs restricts the introduction of repeated topic changes, encouraging writers to stick to a single point or two and limiting the frequency of topic shifters. They therefore occurred in no more than a handful of the 50 blogs we examined. Moreover, departing from the ongoing argument and explicitly breaking from the content of the previous utterance in this way, can dilute the thematic focus of the text and risks undermining the argument. Less topic-knowledgeable readers, may have greater difficulty following the flow and so writers avoid the potential risk of undermining layer readers' comprehension. It also, potentially, adds a greater processing burden for readers as they have to switch from the line of thought they were following and keep a second idea or argument in their heads at the same time. Here for example, the cognitive load placed on readers may be too much if they start 
with little knowledge of the topic:

(34) Nonetheless, it still holds there is a type difference between the procedural punctuations and ones where there are closer links between the policies creating the punctuation. Next, we turn to the low-salience punctuations that receive attention through a single minor topic code but that receive limited or no media attention. (RA35)

Readers of specialist journals are better placed by their greater subject knowledge to roll with these changes, hence the slightly more frequent use of topic shifters in the articles. They can more easily adjust to less linear argumentation, and indeed such topic shifting is often more necessary in the lengthier, more elaborate arguments of the research articles:

(35) We now explore whether the educational activity was linked indirectly to health behaviours through a social network pathway. (RA32)

(36) Regarding the extent to which our independent variables are related to openness at the various stages, we focus on those relationships exhibiting significance above the $5 \%$ level 4 to test whether our hypotheses are verified. (RA48)

Once again, then, we see academic authors fine-tuning their language for particular contexts, altering not only their arguments but the rhetorical choices they employ to make these clear to different groups of readers.

\section{Conclusion}

We have explored the under-researched metadiscourse feature of frame markers and how they function to guide readers by organising the discourse for them in two key academic genres. By focusing on how academics use this feature to recontextualise, in academic blogs material they have recently published in journal articles, we have been able to show important differences in the two rhetorical contexts and the sensitivity writers have to the very different readerships and purposes they are engaged in. We see, for example, that bloggers deploy more frame markers in order to present complex research material to a less homogeneous readership which is less conversant with disciplinary knowledge, and to structure this in a succinct manner in much shorter texts. We have also found considerable variation in the sub-categories across the two genres with more labellers and topic shifters to assist specialists follow more lengthy and complex arguments and greater use of sequencers and goal announcers to assist lay readers to understand connections and get the take-home message. 
The reformulation of scientific material into blogs not only involves reworking the argument and restructuring writer-reader relationships, but also reshaping textual resources. Academics' efforts to set out the direction of the text and their discourse goals supports the view, once again, that the academic blog is more than a crude popularisation borrowing from journalistic or conversational practices. This is a genre which owes a great deal to academic rhetorical conventions and should be considered among the family of academic genres (Zou \& Hyland, 2019, 2020). This is, however, a shift in rhetorical style in response to the more egalitarian and engaging web-mediated context.

We hope our analysis in this paper, by drawing on interactive metadiscourse, will not only increase our knowledge of frame markers, but also contribute to our understanding of the relationship between text and context and the ways that recontextualisation is accomplished in the academic register. We also hope our paper speaks to those who are interested in the growing efforts to 'democratise science' and situate academic research more firmly in public spaces. Increasing numbers of academics are now seeking to take their work to wider audiences by participating in blogs and transforming the research they publish in less accessible venues. Pedagogically, the differences demonstrated in this study between writing for specialists and for lay publics also have implications for students' learning how to accommodate information for different genres, audiences and communicative purposes.

We recognise, of course, that this is a relatively small-scale study, and more needs to be done in this area. We therefore hope our claims are suitably circumspect. Further work might explore more disciplines and examine the forms and frequencies of frame markers in other academic genres. There is also a need to substantiate some of our interpretations concerning authors' motivations and readers' receptions of these features by turning to qualitative methods. The combined lenses of corpus-based analysis with interview data will greatly strengthen these findings. However, we believe that these results offer solid baseline data for such studies as well as providing new insights into academic recontextualisation and the role of an important interactive metadiscourse marker.

\section{References}

Aguilar, Marta. (2008). Metadiscourse in Academic Speech: A Relevance-Theoretic Approach. Peter Lang, Bern.

Andrews, Paul. (2003). Is blogging journalism? Nieman Reports, 57(3), 63-65. 
Anthony, Laurence. (2018). AntConc (Version 3.5.7) [Computer Software]. Tokyo, Japan: Waseda University. Retrieved from: http://www.laurenceanthony.net/software.html Bauman, Richard, \& Briggs, Charles. L. (1990). Poetics and performance as critical perspectives on language and social life. Annual Review of Anthropology, 19, 59-88.

Bernstein, Basil. (1990). Class, codes and control. Vol. 4: the structuring of pedagogic discourse. London: Routledge.

Blanchard, Antoine. (2011). Science blogs in research and popularization of science: Why, how and for whom? In Moira Cockell, Jérôme Billotte, Frédéric Darbellay, \& Francis Waldvogel (Eds.), Common knowledge: The challenge of transdisciplinarity (pp. 219-232). Lausanne, Switzerland: EPFL Press.

Cao, Feng \& Hu, Guangwei. (2014). Interactive metadiscourse in research articles: A comparative study of paradigmatic and disciplinary influences. Journal of Pragmatics, $66,15-31$.

Crismore, Avon., Markkanen Raija., \& Steffensen, Margaret. (1993). Metadiscourse in persuasive writing: a study of texts written by American and Finnish university students. Written Communication, 10, 39-71.

Dahl, Trine. (2004). Textual metadiscourse in research articles: a marker of national culture or of academic discipline? Journal of Pragmatics, 36, 1807-1825.

Djonov, Emelia \& Leeuwen, Theo.Van (2014). Bullet points, new writing and the marketization of public discourse: A critical multimodal perspective. In Djonov, E., \& Zhao, S. M. (Eds.), Critical multimodal studies of popular discourse (pp. 232-250). New York: Routledge.

El-Dakhs, Dina. (2018). Why are abstracts in $\mathrm{PhD}$ theses and research articles different? A genre-specific perspective. Journal of English for Academic Purposes, 36, 48-60.

Fahnestock, Jeanne. (1986). “Accommodating science: The rhetorical life of scientific facts". Written Communication, 3, 275-296.

Fraser, Bruce. (1988). Types of English discourse markers. Acta Linguistica Hungarica, 38(1-4), 19-33.

Gotti, Maurizzio. (2014). Reformulation and recontextualization in popularization discourse. Ibérica, 27, 15-34.

Grafton, Kevin. (2009). Situating the public social actions of blog posts. In J. Giltrow \& D. Stein (Eds.), Genres in the Internet (pp. 85-111). Amsterdam, Netherlands: Benjamins. 
Gruzd, Anatoliy, Staves, Kathleen, \& Wilk, Amanda. (2012). Connected scholars: Examining the role of social media in research practices of faculty using the UTAUT model. Computers in Human Behavior, 28(6), 2340-2350.

Halliday, Michael \& Hasan, Roqiah. (1976). Cohesion in English. London: Longman.

Hansen, Holly E. (2016). The impact of blog-style writing on student learning outcomes: A pilot study. Journal of Political Science Education, 12(1), 85-101.

Hempel, Sussane. \& Degand, Leisbeth. (2008). Sequencers in different text genres: Academic writing, journalese and fiction. Journal of Pragmatics, 40, 676-693.

Hyland, Ken. (1998). Persuasion and Context: The pragmatics of academic discourse. Journal of Pragmatics, 30, 437-455.

Hyland, Ken. (2002). What do they mean? Questions in academic writing. TEXT, 22(4), 529557.

Hyland, Ken. (2005). Metadiscourse. London, Continuum.

Hyland, Ken. (2019). Metadiscourse: Exploring interaction in writing. Bloomsbury Publishing Plc.

Hyland, Ken. \& Jiang, Feng. (2018). Text-organizing metadiscourse: tracking changes in rhetorical persuasion. Journal of Historical Pragmatics. Retrieved from: https://ueaeprints.uea.ac.uk/69402/1/Accepted_manuscript.pdf

Hyland, Ken. \& Tse, Polly. (2004). Metadiscourse in academic writing: A reappraisal. Applied Linguistics, 25(2), 156-177.

Ionescu, Alice. (2019). Topic shifters in Romanian: A contrastive analysis. Journal of Pragmatics, (In Press). Retrieved from https://doi.org/10.1016/j.pragma.2019.02.003

Khedri, Mohsen., Heng, Chan. Swee., \& Ebrahimi, Seyed. Foad. (2013). An exploration of interactive metadiscourse markers in academic research article abstracts in two disciplines. Discourse Studies, 15(3), 319-331.

Kim, Loi. Chek. \& Lim, Jason. Miin-Hwa. (2013). Metadiscourse in English and Chinese research article introductions. Discourse Studies, 15(2), 129-146.

Kouper, Inna. (2010). Science blogs and public engagement with science: Practices, challenges, and opportunities. Journal of Science Communication, 9(1), 1-10.

Kuteeva, Maria. (2016). Research blogs, tweets, and wikis. In: K. Hyland \& P. Shaw (Eds.), The Routledge Handbook of English for Academic Purposes (pp. 433-445). Routledge, London.

Kuteeva, Maria., \& Mauranen, Anna. (2018). Digital academic discourse: Texts and contexts: Introduction. Discourse, Context \& Media, 24, 1-7. 
Ledin, Per \& Machin, David. (2015). How lists, bullet points and tables recontextualize social practice: A multimodal study of management language in Swedish universities. Critical Discourse Studies, 12(4), 463-481.

Lim, Jason. Miin-Hwa., Loi, Chek-Kim., Hashim, Azirah., \& Liu, May Siaw-Mei (2015). Purpose statements in experimental doctoral dissertations submitted to U.S. universities: An inquiry into doctoral students' communicative resources in language education. Journal of English for Academic Purposes, 20, 69-89.

Linell, Per. (1998). Discourse across boundaries: on recontextualisation and the blending of voices in professional discourse. Text \& Talk, 18(2), pp. 143-157.

Luzón, María José. (2013). Public communication of science in blogs: Recontextualizing scientific discourse for a diversified audience. Written Communication, 30(4), 428-457.

Martin, J. R., \& Rose, David. (2003). Working with discourse: Meaning beyond the clause. New York: Continuum

Mauranen, Anna. (2013). Hybridism, edutainment, and doubt: Science blogging finding its feet. Nordic Journal of English Studies, 13(1), 7-36.

Molino, Alessandra. (2010). Personal and impersonal authorial references: A contrastive study of English and Italian Linguistics research articles. Journal of English for Academic Purposes, 9, 86-101.

Mu, Congjun., Zhang, Lawrence. Jun. Ehrich, John., \& Hong, Huaqing. (2015). The use of metadiscourse for knowledge construction in Chinese and English research articles. Journal of English for Academic Purposes, 20, 135-148.

Mur-Dueñas, Pilar. (2011). An intercultural analysis of metadiscourse features in research articles written in English and in Spanish. Journal of Pragmatics, 43, 3068-3079.

Rahman, Mujib. (2004). Abide by the Reader: The Use of Metadiscourse Devices in Scientific Discourse. Nottingham Linguistic Circular, 18, 29-48.

Schiffrin, Deborah. (1987). Discourse markers. Cambridge: Cambridge University Press.

Steel, Karl., Cohen, Jeffrey Jerome, Hurley, Mary Kate, \& Joy, Eileen A. (2012). Why we blog: An essay in four movements. Literature Compass, 9(12), 1016-1032.

Stiles, William B. (1981). Classification of intersubjective illocutionary acts. Language in Society, 10(2), 227-249.

Stoller, Fredricka L. \& Robinson, Marin. S. (2013). Chemistry journal articles: An interdisciplinary approach to move analysis with pedagogical aims. English for Specific Purposes, 32, 45-57. 
Ward, Mary-Helen, \& West, Sandra. (2008). Blogging PhD candidature: Revealing the pedagogy. International Journal of Emerging Technologies and Society, 6(1), 60-71.

Zou, Hang \& Hyland, Ken. (2019). Reworking research: interactions in academic articles and blogs, Discourse Studies, 21(6), 713-733.

Zou, (Joanna) Hang \& Hyland, K. (2020). "Think about how fascinating this is": Engagement in academic blogs across disciplines. Journal of English for Academic Purposes, 43, 100809.

Appendix: Examples of common Frame Markers (not exhaustive)

\section{a) Sequencing}

finally

First/ Firstly

First of all

Last/ lastly

Next

thus, so, there are three reasons for this (etc.) + listing (a,b,c, etc) numbering $(1,2,3$, etc $)$

Second/Secondly bullet pointing

subsequently

Then

Third/Thirdly

to begin

to start with

\section{b) label stages}

all in all

at this point

at this stage

by far

for the moment

in a word

in brief

in conclusion

in short

in sum

in summary

on the whole

overall

so far

thus far 
to conclude

to repeat

to sum up

to summarise

c) announce goals

(in) this chapter

(in) this part

(in) this section

aim

desire to

focus

goal

intend to

intention

objective

purpose

seek to

to better understand

want to

wish to

would like to

d) shift topic

back to

digress

in regard to

move on

now

regarding

resume

return to

revisit

shift to

so

to look more closely

turn to

well

with regard to 